\title{
Soluble receptor for advanced glycation end-products enhanced the production of IFN- $\gamma$ through the NF- $\kappa B$ pathway in macrophages recruited by ischemia/reperfusion
}

\author{
XIULING ZHANG ${ }^{1}$, XIANXIAN CAO $^{1}$, MENGQIU DANG $^{1}$, HONGXIA WANG $^{2}$, BUXING CHEN $^{1}$, \\ FENGHE DU ${ }^{1,3}$, HUIHUA LI ${ }^{4,5}$, XIANGJUN ZENG ${ }^{2}$ and CAIXIA GUO ${ }^{1}$ \\ ${ }^{1}$ Department of Cardiology, Beijing Tian Tan Hospital, Capital Medical University, Beijing 100070; \\ ${ }^{2}$ Department of Physiology and Pathophysiology, Capital Medical University, Beijing 100069; ${ }^{3}$ Department of Geriatrics, \\ Beijing Tian Tan Hospital, Capital Medical University, Beijing 100070; ${ }^{4}$ Department of Cardiology, \\ Institute of Cardiovascular Disease, First Affiliated Hospital of Dalian Medical University, Dalian, Liaoning 116011; \\ ${ }^{5}$ Department of Nutrition and Food Hygiene, School of Public Health, Advanced Institute of \\ Medical Sciences, Dalian Medical University, Dalian, Liaoning 116044, P.R. China
}

Received October 10, 2018; Accepted March 21, 2019

DOI: $10.3892 / \mathrm{ijmm} .2019 .4152$

\begin{abstract}
The current study investigated the role of sRAGE in the production of IFN- $\gamma$ in macrophages with I/R treatment. The number of macrophages in myocardial tissues treated with I/R with or without SRAGE was determined via immunohistochemical staining. Proliferative activity of macrophages was analyzed by a 5-BrdU incorporation assay. Differentiation of macrophages was detected via immunofluorescence staining of iNOS (M1 macrophage marker). IFN- $\gamma$ production, due to
\end{abstract}

Correspondence to: Professor Caixia Guo, Department of Cardiology, Beijing Tian Tan Hospital, Capital Medical University, 119 West Road of South 4th Ring Road, Fengtai, Beijing 100070, P.R. China

E-mail: cxgbb@163.com

Dr Xiangjun Zeng, Department of Physiology and Pathophysiology, Capital Medical University, 10 You An Men Wai Xi Tou Tiao, Beijing 100069, P.R. China

E-mail: megan_zeng@163.com

Abbreviations: IFN- $\gamma$, interferon- $\gamma$; sRAGE, soluble receptor for advanced glycation end-products; RAGE, receptor for advanced glycation end-products; $\mathrm{I} / \mathrm{R}$, ischemia/reperfusion; NF- $\mathrm{BB}$, nuclear factor- $\kappa \mathrm{B}$; p-NF- $\kappa \mathrm{B}$, phosphorylated NF- $\kappa \mathrm{B}$; I $\mathrm{B}$, inhibitory $\kappa \mathrm{B}$; p-I $\kappa$ B, phosphorylated I $\mathrm{KB}$; IKK, I $\mathrm{B}$ kinase complex; p-IKK, phosphorylated IKK; GAPDH, glyceraldehyde-3-phosphate dehydrogenase; 5-BrdU, 5-Bromo-2'-Deoxyuridine; ChIP, chromatin immunoprecipitation; H\&E, hematoxylin and eosin staining; CD68, cluster of differentiation 68; Ly6g, lymphocyte antigen 6 complex, locus G; SD, standard deviation; P, P-value; iNOS, inducible nitric oxide synthase; IL-12, interleukin 12; IL-6, interleukin 6; PVDF, polyvinylidene fluoride

Key words: sRAGE, IFN- $\gamma$, ischemia/reperfusion, macrophage, $\mathrm{NF}-\kappa \mathrm{B}$
sRAGE stimulation, in Raw 264.7 macrophages and the NF- $\kappa$ B signaling pathway were measured using western blotting. A ChIP assay was used to examine the interactions between $\mathrm{NF}-\kappa \mathrm{B}$ and the promoter of IFN- $\gamma$. The results showed that the number of macrophages in I/R-treated myocardial tissues was increased following sRAGE infusion. Proliferation of macrophages was increased significantly in the presence of sRAGE; after I/R treatment, the cells preferred to differentiate into M1 macrophages. IFN- $\gamma$ expression in Raw 264.7 macrophages was suppressed by an NF- $\kappa \mathrm{B}$ inhibitor (Bay117082) but enhanced by sRAGE, with or without I/R treatment. Furthermore, sRAGE increased the phosphorylation of $\mathrm{I} \kappa \mathrm{B}$, IKK and NF- $\kappa \mathrm{B}$, as well as the translocation of $\mathrm{NF}-\kappa \mathrm{B}$ into the nucleus of Raw 264.7 macrophages, with or without I/R treatment. ChIP results showed that sRAGE promoted NF- $\kappa \mathrm{B}$ binding to the promoter of IFN- $\gamma$ in Raw 264.7 macrophages. Therefore, the findings of the present study indicated that sRAGE protected the heart from I/R injuries, which might be mediated by promoting infiltration and the differentiation of macrophages into $\mathrm{M} 1$, which would then synthesize and secrete IFN $-\gamma$ through activating the NF- $\kappa \mathrm{B}$ signaling pathway.

\section{Introduction}

With improvements in therapeutic methodology methods over the past 10 years, ischemic heart disease can be treated by reperfusion, such as cardiac bypass surgery percutaneous coronary intervention. However, in some patients, myocardial dysfunction and tissue damage may be further aggravated by reperfusion. This is called ischemia/reperfusion injury (1). Therefore, methods that may prevent ischemia/reperfusion injury are being explored. Currently, the prevention and treatment of myocardial ischemia/reperfusion injury include ischemic pre-conditioning (2), post-conditioning (3), and remote ischemic conditioning (4). These treatments promote the release of endogenous protective substances, such as protein kinase C (5), tilianin (6), penehyclidine hydrochloride (7), 
and soluble receptor for advanced glycation end products (sRAGE) (8). The protective mechanisms of these endogenous substances are considered to have common properties, such as the inhibition of apoptosis and of mitochondrial damage. Furthermore, sRAGE not only showed a protective effect against cardiac reperfusion injury, but also against a variety of inflammatory reactions.

sRAGE can act as a 'decoy' for RAGE ligands, just as a 'sponge' that binds with ligands of the RAGE such as HMGB1, AGEs, and S100 (9). sRAGE can be produced by proteolytic cleavage of ADAM10 from the plasma membrane, and it consists of a coupled VC1 domain and an independent $\mathrm{C} 2$ domain (10-12). In addition to being a competitive inhibitor of RAGE, sRAGE also promotes the secretion of cytokines and exerts pro- and anti-inflammatory properties (13-15).

Previous studies have shown that sRAGE may significantly increase IFN- $\gamma$ expression, which then inhibits the I/R injury-induced apoptosis of cardiomyocytes (16). However, the mechanism underlying sRAGE-promoted IFN- $\gamma$ release in the reperfused heart remains unclear. IFN- $\gamma$ is a cytokine secreted by mononuclear macrophages $(17,18)$, lymphocytes and NK cells (19). A variety of convergent signaling transduction pathways are involved in the transcriptional regulation of IFN- $\gamma(20)$. This raises a query regarding the mechanisms by which sRAGE increases the release of IFN- $\gamma$ in the reperfused heart, the cellular source(s) of IFN- $\gamma$, and the signaling pathways mediating IFN- $\gamma$ synthesis and release. In the present study, mice and macrophages were each used to simulate ischemia/reperfusion, in order to evaluate the mechanisms underlying the effect of sRAGE on IFN- $\gamma$ expression in the $\mathrm{I} / \mathrm{R}$ heart.

\section{Materials and methods}

Experimental animal model. A total of 20 six-week-old (18-22 g), male C57BL/6J mice were purchased from Vital River Laboratories Co., Ltd. (Beijing, China). The relative humidity of the animal room was $45 \%$ and the ambient temperature was $24^{\circ} \mathrm{C}$, with a $12 / 12 \mathrm{~h}$ light/dark cycle and ad libitum diet and drinking water. All animal studies followed the Animal Care and Use Committee of Capital Medical University (Beijing, China) (permit number: AEEI-2016-055). Mice were anesthetized with isoflurane at a fraction of $2 \%$ in volume. The left anterior descending coronary artery was ligated for $30 \mathrm{~min}$, and then reperfused for $24 \mathrm{~h}$ to create an ischemia/reperfusion model (21). Mice in the sham group were subjected to the same surgical procedure except for the ligation of the blood vessels. sRAGE (00112-01-100; AVISCERA Bioscience, CA, USA; $2 \mu \mathrm{g} /$ mouse) or an equal volume of saline was administered into the heart prior to surgery.

The mice subjected to $I / R$ surgery were then randomly divided into the $I / R$ group ( $/ \mathrm{R}$ group; $\mathrm{n}=6$ ), injected with vehicle, and the sRAGE treatment group (I/R+sRAGE group; $\mathrm{n}=6$ ), injected with sRAGE. The mice without ligated blood vessels were randomly divided into the control group (sham group; $n=6$ ), injected with vehicle, and the sRAGE treatment group (sRAGE group; $n=6$ ), injected with sRAGE. After the mice were anesthetized by intraperitoneal injection of tribromoethanol, the heart was removed, and fixed in $10 \%$ formalin or stored at $-80^{\circ} \mathrm{C}$ for analysis.
Immunohistochemistry and hematoxylin and eosin staining. Tissue sections $(4-\mu \mathrm{m})$ were used to perform immunostaining for CD68 and ly6g with a rabbit anti-CD68 antibody (ab125212; Abcam, Cambridge, UK) and a goat anti-rat $\operatorname{lgG}$ (horseradish peroxidase) (ab97057; Abcam). CD68 and ly6g in the tissue were identified using the horseradish peroxidase-DAB detection method. Hematoxylin and eosin staining was performed following the manufacturer's instructions. Sections were observed using an Olympus BX63 microscope (magnification indicated in the figures) (Olympus America, Inc., Center Valley, PA, USA).

$I / R$ protocol in macrophages. The Raw264.7 cell line was purchased from Beina Chuanglian Biotechnology Institute (BNCC100584; BBCI, Beijing, China). After being synchronized for 6-8 h, the cells were incubated with 'Ischemia Buffer' and $2 \% \mathrm{O}_{2}$ for $2 \mathrm{~h}$. Then, the 'Ischemia Buffer' was replaced with a serum-free medium for incubation at $37^{\circ} \mathrm{C}$ and $5 \% \mathrm{CO}_{2}$ to replicate the ischemia-reperfusion model. The 'Ischemia Buffer' comprised: $118 \mathrm{mmol} / 1 \mathrm{NaCl}, 24 \mathrm{mmol} / 1 \mathrm{NaHCO}_{3}$, $1.0 \mathrm{mmol} / 1 \mathrm{NaH}_{2} \mathrm{PO}_{4}, 2.5 \mathrm{mmol} / 1 \mathrm{CaCl}_{2} \cdot 2 \mathrm{H}_{2} \mathrm{O}, 1.2 \mathrm{mmol} / 1$ $\mathrm{MgCl}_{2}, 20 \mathrm{mmol} / 1$ lactate, $16 \mathrm{mmol} / \mathrm{l} \mathrm{KCl}$, and $10 \mathrm{mmol} / 1$ deoxyglucose. The cells in the control group were cultured in medium containing $10 \% \mathrm{FBS}$ at $37^{\circ} \mathrm{C}$ and $5 \% \mathrm{CO}_{2}$. Bayl17082 (ab141228: Abcam), an inhibitor of NF- $\mathrm{kB}$, and sRAGE were available and used during all processes in the treated groups.

Cells treated with $I / R$ were randomly divided into the $I / R$ group ( $/ / R$ group, $n=3$ ), which was stimulated with PBS 30 min prior to I/R, the sRAGE group (I/R+sRAGE group, $\mathrm{n}=3)$, which was stimulated with sRAGE (900 $\mathrm{ng} / \mathrm{ml})$ 30 min prior to $\mathrm{I} / \mathrm{R}$, and the sRAGE and Bay 117082 group (I/R+sRAGE+Bayl17082 group, $\mathrm{n}=3$ ), which was stimulated with sRAGE $(900 \mathrm{ng} / \mathrm{ml})$ and Bayl17082 $(5 \mu \mathrm{M}) 30 \mathrm{~min}$ prior to I/R. Control cells were randomly divided into three different groups in the same manner as the I/R-treated cells (sham group, sRAGE group, sRAGE+Bay117082 group, $n=3$ for each group).

Proliferation assay of macrophages. Macrophages were treated with recombinant sRAGE proteins for $24 \mathrm{~h}$ prior to I/R treatment. 5-BrdU (10 $\mu \mathrm{m}$; B5002-1G; Sigma-Aldrich; Merck $\mathrm{KGaA}$, Darmstadt, Germany) was used during the process to label proliferating cells (22). Cells were fixed in $4 \%$ paraformaldehyde in phosphate-buffered saline for $15 \mathrm{~min}$ at room temperature, followed by incubation with $2 \mathrm{~N} \mathrm{HCl}$ for $1 \mathrm{~h}$ and $0.2 \%$ Triton-X solution in water for $45 \mathrm{~min}$, then blocked with $1 \%$ FBS for $1 \mathrm{~h}$. Next, cells were incubated with primary antibodies for 5-BrdU (ab1893; Abcam) at $4^{\circ} \mathrm{C}$ overnight. Donkey Anti-Sheep IgG H\&L (Alexa Fluor ${ }^{\circledR}$ 647) and pre-adsorbed secondary antibodies (ab150155; Abcam) were incubated for $1 \mathrm{~h}$ at room temperature. Cell nuclei were stained with 4',6-diamidino-2-phenylindole (DAPI; ZLI-9557; ZSGB-BIO, Beijing, China). Slices were visualized via confocal microscopy (TCS SP8 X, Leica Camera AG, Wetzlar, Germany). The number of 5-BrdU-positive cells was calculated in at least 6 random fields in each dish per group. Results were expressed as the percentage of 5-BrdU-positive cells among total cells.

Analyses of macrophage differentiation. After treatment, the cells were fixed in $4 \%$ paraformaldehyde in PBS at room 
temperature for $15 \mathrm{~min}$, followed by $0.2 \%$ Triton-X solution in PBS for $7 \mathrm{~min}$. After blocking in 1\% FBS for $1 \mathrm{~h}$, the cells were incubated with a primary anti-iNOS antibody (ab15323; Abcam) and an Alexa Fluor 488-labeled goat anti-rabbit antibody (ab150077; Abcam). Cell nuclei were stained with DAPI (ZLI-9557; ZSGB-BIO). Slices were visualized using a fluorescence microscope (930642; Nikon Corporation, Chiyoda-Ku, Tokyo, Japan). The number of iNOS-positive cells in at least 6 random fields in each dish per group was calculated. Results were expressed as the percentage of iNOS-positive cells among total cells.

Detection of IFN- $\gamma$ mRNA, IL-6, and IL-12 in macrophages. Total RNA was extracted from macrophages using TRIzol reagent (Invitrogen; Thermo Fisher Scientific, Inc., Waltham, MA, USA). cDNA was synthesized from $2 \mu \mathrm{g}$ of total RNA using a Prime Script RT Reagent Kit with a gDNA Eraser kit (RR047A; TaKaRa Bio, Kusatsu, Japan) following the manufacturer's instructions. Expression of IFN- $\gamma$, IL-6 and IL-12 mRNA was analyzed via q-PCR using SYBR-Green PCR Master Mix (RR420A; TaKaRa Bio) with a 7500 Real-Time PCR System. The primers for IFN- $\gamma$ were 5'-AGCAAGGCG AAAAAGGATGC-3' (forward) and 5'-TCATTGAATGCT TGGCGCTG-3' (reverse). The primers for IL-6 were 5'-CTG GAGCCCACCAAGAACGA-3' (forward) and 5'-GCCTCC GACTTGTGAAGTGGT-3' (reverse). The primers for IL-12 were 5'-TCATGGACATGATGGGGCTG-3' (forward) and 5'-TCCCTCTGGGAACGATGTCT-3' (reverse).

Western blot analysis. Proteins extracted from Raw264.7 macrophages were separated by $8-15 \%$ SDS-PAGE followed by electro-blotting onto PVDF membranes. After blocking in $5 \%$ milk for $1 \mathrm{~h}$ at room temperature, the PVDF membrane was incubated overnight at $4^{\circ} \mathrm{C}$ with the following primary antibodies: Mouse anti-IFN- $\gamma$ (37895; Abcam), rabbit anti-phospho-IKK (2078), rabbit anti-IKK (2370), rabbit

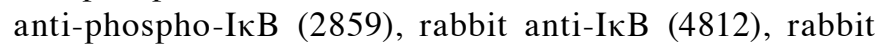

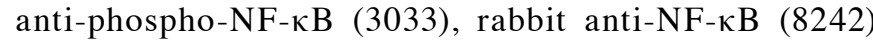
GAPDH (5174; all from Cell Signaling Technology, Inc., Danvers, MA, USA), and anti-Histone H3 (ab1791; Abcam). Next, the PVDF membrane was washed thrice with TBST (20 mM Tris, $150 \mathrm{mM} \mathrm{NaCl}$, containing 0.05\% Tween-20, $\mathrm{pH}$ 7.4) followed incubation with a donkey anti-mouse IgG-HRP (sc-2314; Santa Cruz Biotechnology, Inc., Dallas, TX, USA) or an anti-rabbit HRP-linked secondary antibody (707; Cell Signaling Technology, Inc.) for $1 \mathrm{~h}$ at room temperature. The FluorChem ${ }^{\mathrm{TM}}$ FC3 system (Protein-Simple, Santa Clara, CA, USA) was used for imaging of the strips on the PVDF membrane that were developed using Immobilon $^{\mathrm{TM}}$ Western Chemiluminescent HRP Substrate (WBKLS0500; EMD Millipore, Billerica, MA, USA).

Extraction of cytoplasmic and nuclear protein. In order to examine translocation of $\mathrm{NF}-\kappa \mathrm{B}$, cytoplasmic and nuclear proteins were extracted using Minute $^{\mathrm{TM}}$ Cytoplasmic and Nuclear Extraction Kit (SC-003, Invent Biotechnologies, Eden Prairie, Minnesota, USA) according to the manufacturer's protocol and analyzed with western blot. Briefly, the cells were collected in $300 \mu$ l cytoplasmic extraction buffer, incubated on ice for $5 \mathrm{~min}$, and centrifuged at $21,130 \mathrm{x} \mathrm{g}$ for $5 \mathrm{~min}$ at $4^{\circ} \mathrm{C}$ to extract cytoplasmic proteins. The precipitates were resuspended with $150 \mu \mathrm{l}$ nuclear extraction buffer and centrifuged $21,130 \mathrm{x} \mathrm{g}$ for $5 \mathrm{~min}$ at $4^{\circ} \mathrm{C}$ to extract nuclear proteins.

Chromatin immunoprecipitation (ChIP) assay. A ChIP assay was performed according to the protocol of the SimpleChIP ${ }^{\circledR}$ Enzymatic Chromatin IP Kit (9002; Cell Signaling Technology, Inc.). Briefly, macrophages were harvested $24 \mathrm{~h}$ after I/R or control treatment with or without sRAGE $(900 \mathrm{ng} / \mathrm{ml})$ with ChIP buffer followed by sonication to obtain 200-1,000 bp DNA fragments. Immunoprecipitation was performed with anti NF- $\kappa \mathrm{B}$ (8242; Cell Signaling Technology, Inc.) at $4^{\circ} \mathrm{C}$ overnight. The DNA fragments were eluted from antibody/protein $\mathrm{G}$ microbeads followed by purification with DNA purification spin columns (10010; Cell Signaling Technology, Inc.). The primers for IFN- $\gamma$ were designed for the $-2,000 \mathrm{bp}$ upstream region used for the immunoprecipitation assay with qPCR, according to the instructions of the kit. PCR was performed with the following primers: 5-CATGGCCAAAGGAACTGC AC-3 (forward) and 5-TGGCTATGGGTGCAGACTTG-3 (reverse).

Statistical analysis. SPSS (version 16.0; IBM Corp., Armonk, NY, USA) was used to process the experimental data. Experimental data are expressed as the mean \pm standard deviation (SD). Differences among the groups were tested using one-way ANOVA. Comparisons between two groups were evaluated using the least significant differences (LSD) test. $\mathrm{P}<0.05$ was considered to indicate a statistically significant difference.

\section{Results}

sRAGE improves heart function in mice after $I / R$. To explore the effects of sRAGE in I/R-treated heart, cardiac function was measured after $I / R$ with or without sRAGE. The results showed that cardiac output and stroke volume were decreased in I/R-treated mice compared with in the sham group. Cardiac output was increased from $12.68 \pm 3.57$ to $17.71 \pm 1.42 \mathrm{ml} / \mathrm{min}$, and stroke volume was increased from $21.60 \pm 5.16$ to $30.44 \pm 1.89 \mu \mathrm{l}$ by sRAGE in I/R-treated mice $(\mathrm{P}<0.05$; Fig. 1A-C).

SRAGE increased macrophage infiltration in myocardial tissue after $I / R$. The hearts were harvested $24 \mathrm{~h}$ after I/R or sham treatment with or without sRAGE. The results from hematoxylin and eosin and immunohistochemistry staining showed that the numbers of inflammatory cells and neutrophils were decreased in I/R-treated myocardial tissues with sRAGE compared with I/R-treated tissues without sRAGE (Fig. 1D and F). Results of immunohistochemistry tests showed that the proportion of positive macrophages (CD68 positive) was increased in I/R myocardial tissues treated with sRAGE $(37.92 \pm 3.46, n=6)$ or without sRAGE $(13.97 \pm 3.46$, $\mathrm{n}=6)$ compared with the sham group $(0.99 \pm 0.35, \mathrm{n}=6)$ $(\mathrm{P}<0.05)$ (Fig. 1D and E). Notably, macrophages recruited in sRAGE-treated I/R hearts were 1.9-3.8-fold that in I/R hearts $(n=6 ; P<0.05)$ while no such effects were observed in the sham group with or without sRAGE treatment $(0.99 \pm 0.35$ in the sham group; $1.42 \pm 0.89$ in the sRAGE group; $n=6 ; P>0.05)$. 
A

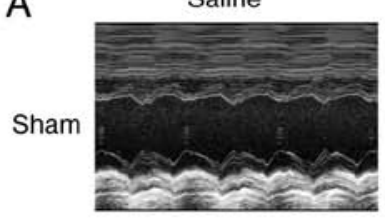

I/R

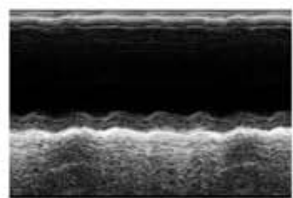

SRAGE
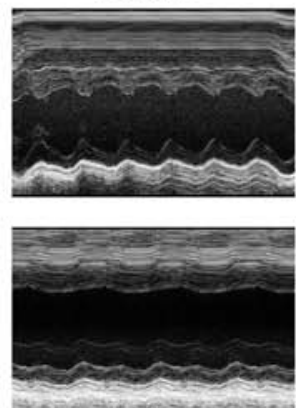

B

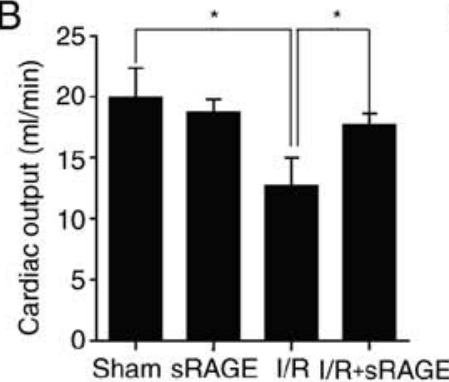

C

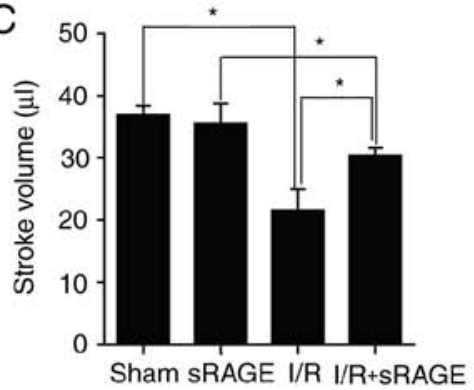

D
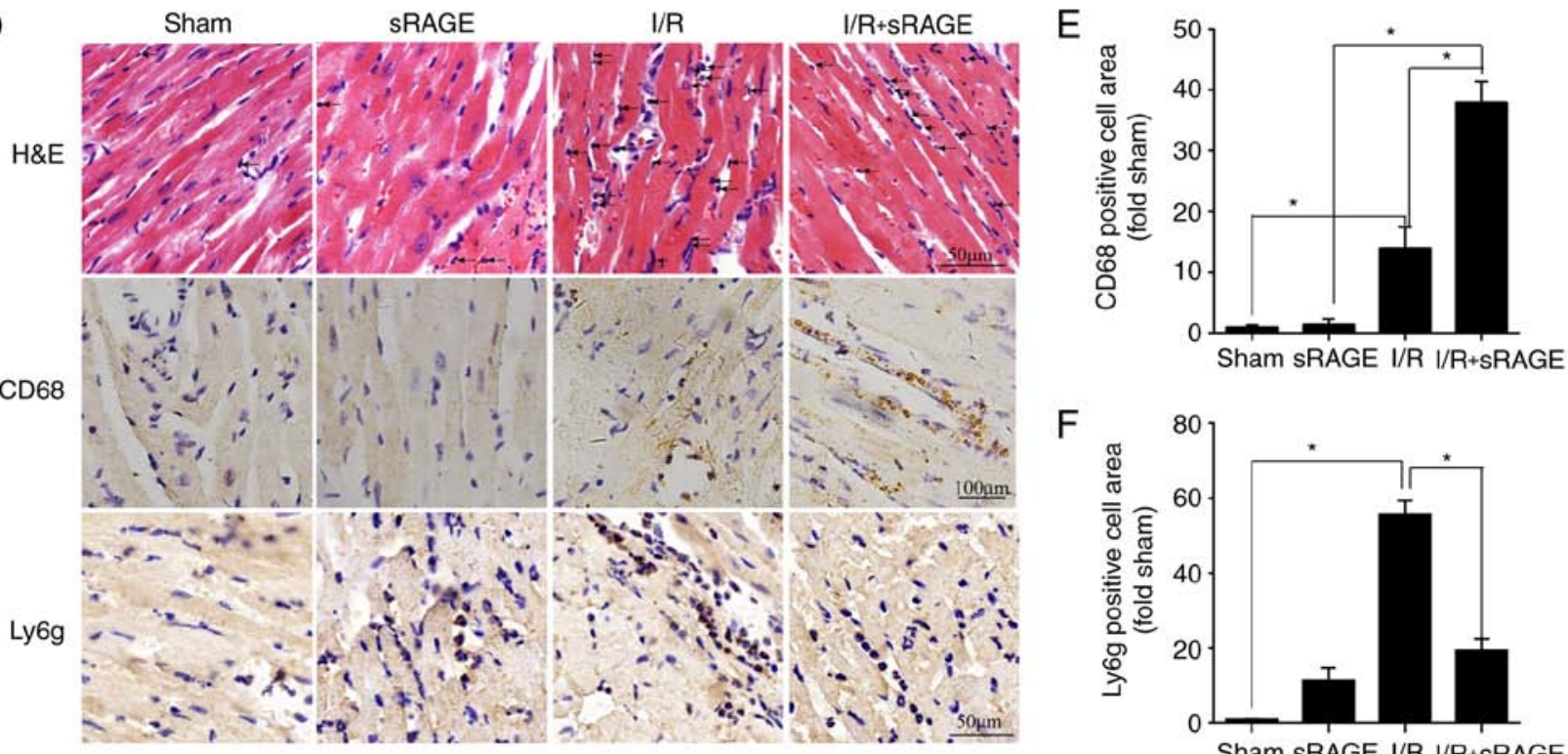

$\mathrm{F}$

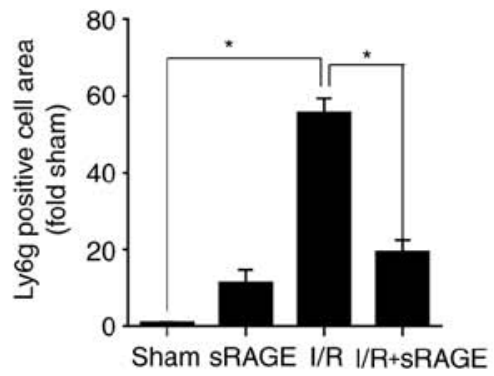

Figure 1. sRAGE increased macrophage infiltration in myocardial tissue following I/R. (A) Representative images of the M-mode of echocardiography for each group. (B) The cardiac output was improved by sRAGE in I/R-treated heart. (C) Stroke volume was improved by sRAGE in the I/R-treated heart. (D) Representative images of hematoxylin and eosin staining, immunohistochemistry for CD68 and Ly6g. (E) Macrophage infiltration was expressed through the quantification of CD68-positive cells. (F) Neutrophil infiltration was expressed through the quantification of Ly6g-positive cells. The data are expressed as the mean $\pm \mathrm{SD}\left(\mathrm{n}=6,{ }^{*} \mathrm{P}<0.05\right)$. sRAGE, soluble receptor for advanced glycation end-products; I/R, ischemia/reperfusion; H\&E, hematoxylin and eosin staining; CD68, cluster of differentiation 68; Ly6g, lymphocyte antigen 6 complex, locus G; SD, standard deviation; P, P-value.

These results suggested that exogenous administration of sRAGE attenuated the inflammatory response and reduced neutrophils, but induced the recruitment of macrophages in the I/R-treated heart.

SRAGE stimulated macrophage proliferation and differentiation. To detect the proliferation of macrophages, a 5 -BrdU-incorporation assay was used. The results indicated that 5-BrdU-positive macrophages in I/R-treated cells $(2.29 \pm 0.284)(\mathrm{n}=3 ; \mathrm{P}<0.05)$ increased compared with in control cells $(1.00 \pm 0.191)(\mathrm{n}=3 ; \mathrm{P}<0.05)$ (Fig. $2 \mathrm{~A}$ and B). Notably, sRAGE increased the number of 5-BrdU-positive macrophages to $5.25 \pm 0.123$ in I/R-treated cells and $2.73 \pm 0.451$ in PBS treated cells $(n=3 ; P<0.05)$ (Fig. $2 A$ and B). These results suggested that exogenous administration of sRAGE stimulates macrophage proliferation.

To detect the differentiation of macrophages, immunofluorescence analysis of the M1 macrophage marker, iNOS, was used. The results showed that the percentage of iNOS-positive macrophages was significantly increased from $0.99 \pm 0.154$ in the control group to $2.48 \pm 0.541$ following $I / R(n=3 ; P<0.05)$, and further enhanced to $7.69 \pm 1.533$ following sRAGE treatment $(\mathrm{n}=3 ; \mathrm{P}<0.05)$ (Fig. $2 \mathrm{C}$ and $\mathrm{D})$. Additionally, sRAGE enhanced the number of iNOS-positive macrophages to $3.57 \pm 0.781$ as well $(n=3 ; P<0.05)$ (Fig. $2 C$ and $D)$. In order to further confirm the effect of exogenous administration of sRAGE on Raw 264.7 cell polarization, levels of IL-6 and IL-12 (markers for M1) were detected using a q-PCR assay. The results showed that the levels of IL- 6 and IL-12 were increased in I/R-treated macrophages with sRAGE treatment $(\mathrm{n}=3 ; \mathrm{P}<0.05)$ (Fig. 2E and F). These results demonstrated that exogenous administration of sRAGE stimulated the differentiation of macrophages to M1.

SRAGE augmented the expression of IFN- $\gamma$ in macrophages. Total RNA from Raw264.7 cells was used for IFN- $\gamma$ detection via $\mathrm{qPCR}$. The results showed that the level of IFN- $\gamma$ was increased in a time dependent manner in I/R-treated macrophages with sRAGE treatment, where the highest value was reached at $12 \mathrm{~h}(\mathrm{n}=3 ; \mathrm{P}<0.05)$; (Fig. 3A). The proteins from Raw264.7 cells were used for IFN- $\gamma$ detection using western blot. The results showed that the level of IFN- $\gamma$ was 
A
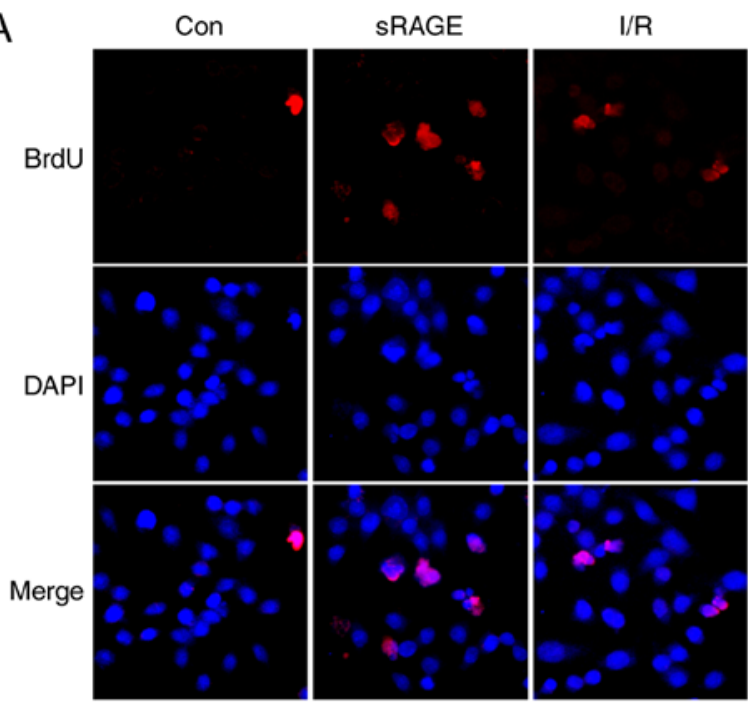

/R

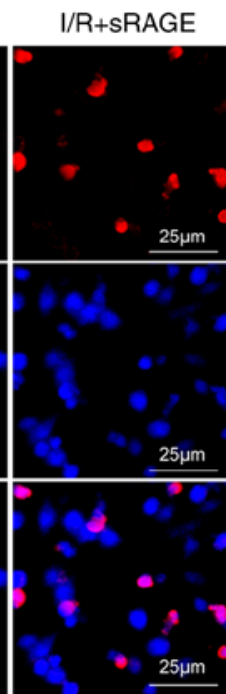

C

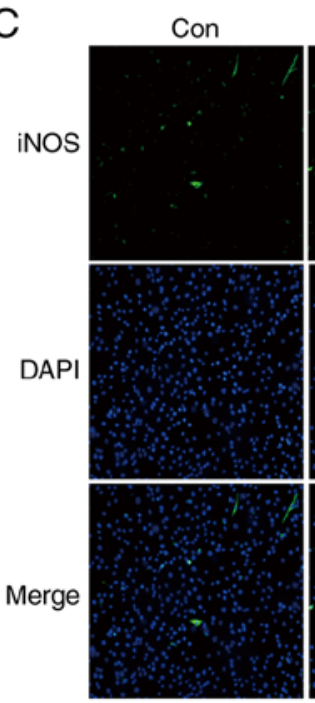

SRAGE

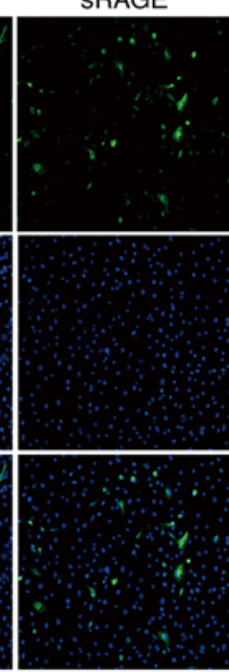

I/R

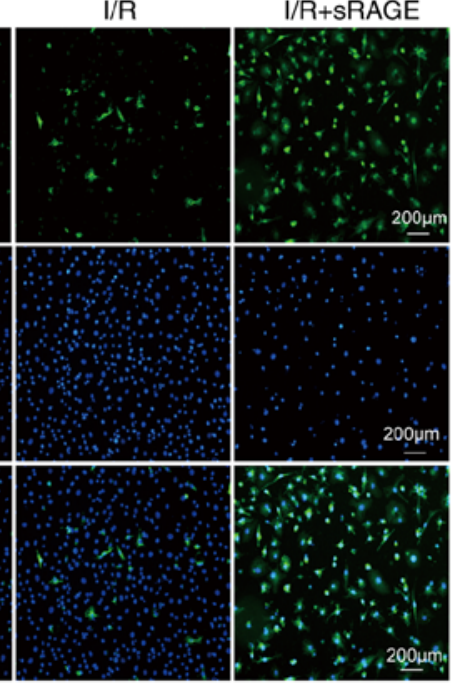

B
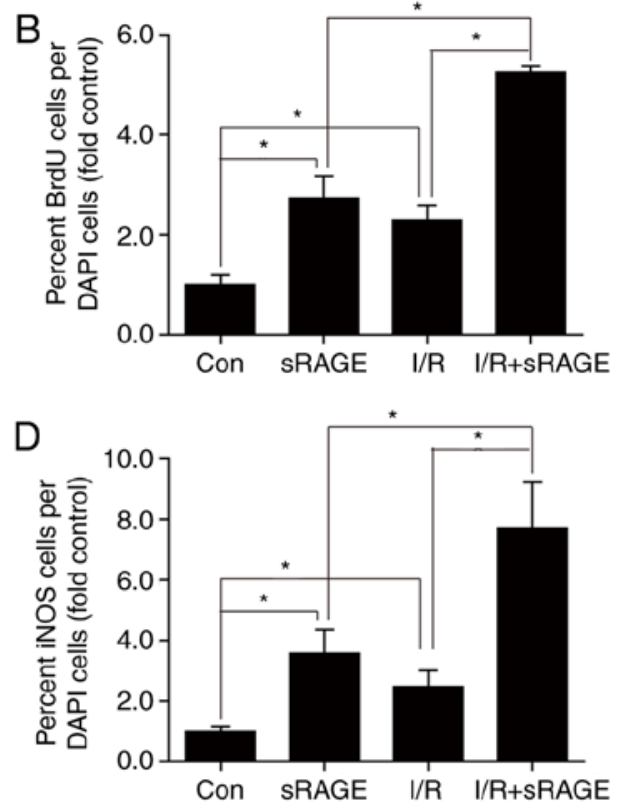

E
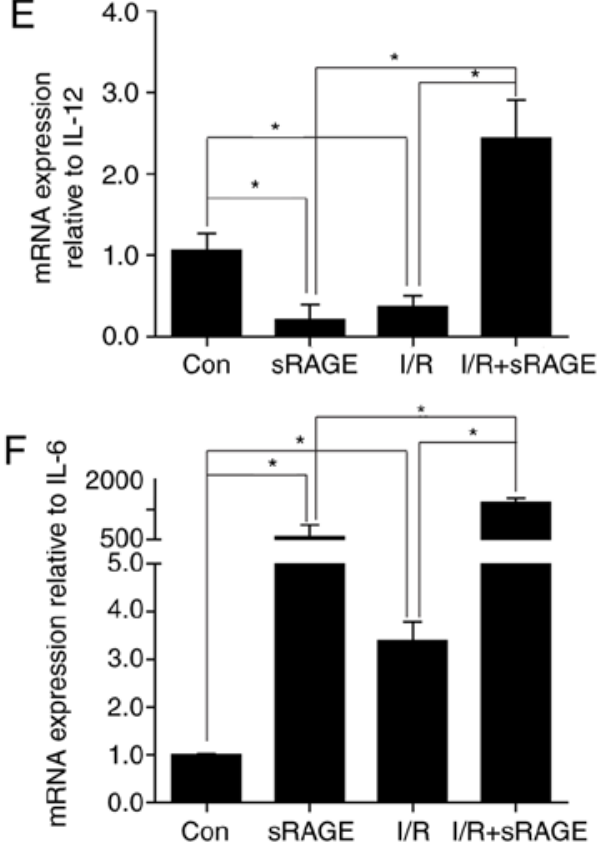

Figure 2. sRAGE stimulated macrophage proliferation and differentiation. (A) Representative images of immunofluorescence staining for 5-BrdU in macrophages. Red shows 5-BrdU-positive macrophages; blue shows the nucleus. Bar, $25 \mu \mathrm{m}$. (B) BrdU+ and BrdU- nuclei among the macrophages were counted, and the percentages of BrdU+ nuclei were calculated (fold sham). (C) Representative images of immunofluorescence staining for iNOS in macrophages. Green shows iNOS-positive macrophages, blue shows the nucleus. Bar, $200 \mu \mathrm{m}$. (D) The data for iNOS-positive cells were expressed as a percentage of the total nuclei. (E) Quantitative data of the mRNA levels of IL-12 in macrophages. (F) Quantitative data of the mRNA levels of IL-6 in macrophages. The data are expressed as the mean $\pm \mathrm{SD}\left(\mathrm{n}=3,{ }^{*} \mathrm{P}<0.05\right)$. sRAGE, soluble receptor for advanced glycation end-products; $\mathrm{I} / \mathrm{R}$, ischemia/reperfusion; 5-BrdU, 5-Bromo-2'-Deoxyuridine; iNOS, inducible nitric oxide synthase; IL, interleukin.

increased to $1.70 \pm 0.60$ in I/R-treated cells compared with control cells $(1.00 \pm 0.124) ;(n=3 ; P<0.05)$; (Fig. 3B and C). Notably, sRAGE increased the level of IFN- $\gamma$ to $22.68 \pm 0.37$ in I/R-treated cells and $1.58 \pm 0.43$ in PBS treated cells $(n=3$; $\mathrm{P}<0.05$ ); (Fig. 3B and C). These results suggested that sRAGE augmented IFN $-\gamma$ expression in macrophages with $\mathrm{I} / \mathrm{R}$ treatment.

sRAGE activated $N F-\kappa B$ signaling pathway in macrophages. To detect the effect of the NF- $\kappa$ B signaling pathway on IFN- $\gamma$ expression in macrophages, the level of phosphorylated IKK,
$\mathrm{I \kappa B}, \mathrm{NF}-\kappa \mathrm{B}$ in cells treated with or without $\mathrm{I} / \mathrm{R}$, in the presence or absence of sRAGE, was analyzed using western blotting. Results indicated that $\mathrm{p}-\mathrm{NF}-\kappa \mathrm{B}$ levels were increased to $1.87 \pm 0.23$ in I/R-treated cells compared with control cells, and were further increased to $3.15 \pm 0.23$ by sRAGE in I/R-treated cells $(\mathrm{n}=3$; $\mathrm{P}<0.05)$; (Fig. 4A and B). Additionally, sRAGE also increased the level of $\mathrm{p}-\mathrm{NF}-\kappa \mathrm{B}$ to $2.29 \pm 0.44$ in control macrophages $(n=3 ; P<0.05)$ (Fig. $4 A$ and $B)$. The results also showed that sRAGE increased $\mathrm{p}$-I $\mathrm{BB}$ level to $1.47 \pm 0.13$ in I/R-treated cells and $1.34 \pm 0.05$ in PBS treated cells $(n=3$; $\mathrm{P}<0.05$ ) (Fig. 4A and C). At the same time, the results showed 
A

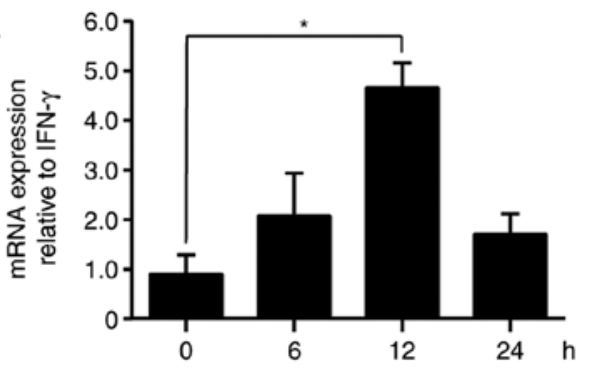

B

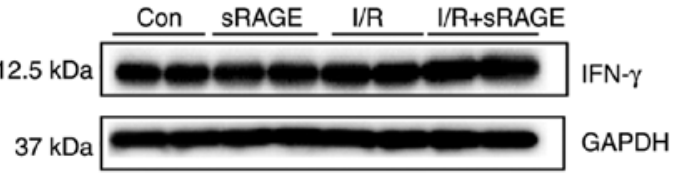

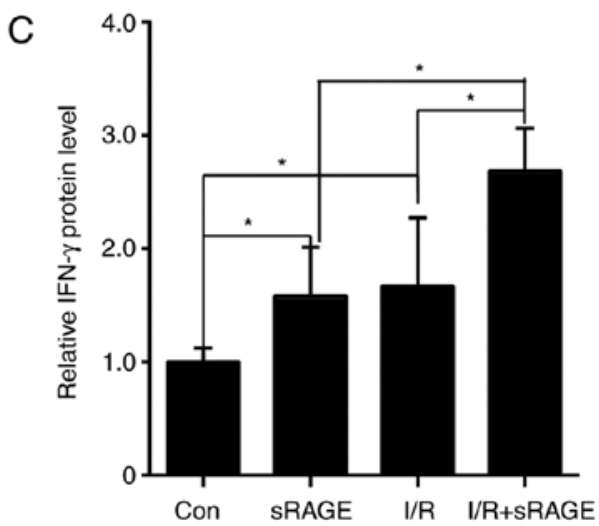

Figure 3. sRAGE augmented IFN- $\gamma$ expression in macrophages. (A) Quantitative data of the mRNA levels of IFN- $\gamma$ in macrophages. (B) Representative images of western blotting for IFN- $\gamma$. (C) Quantification of relative protein levels of IFN- $\gamma$ in macrophages. The data are expressed as the mean $\pm \mathrm{SD}\left(\mathrm{n}=3,{ }^{*} \mathrm{P}<0.05\right)$. sRAGE, soluble receptor for advanced glycation end-products; I/R, ischemia/reperfusion; IFN, interferon.
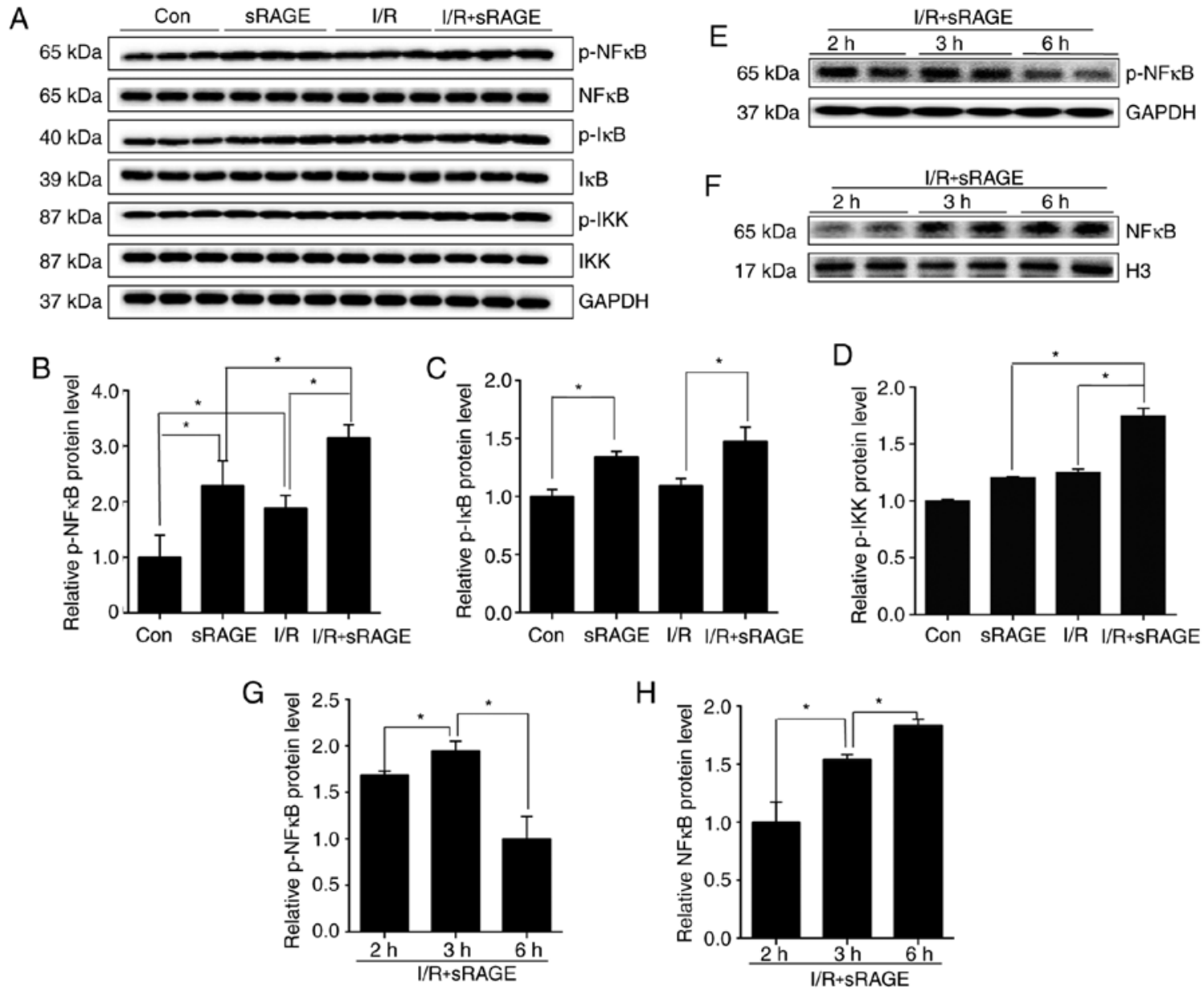

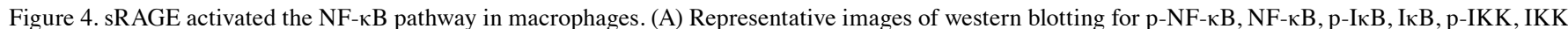
and GAPDH in macrophages. (B) Quantification of relative protein levels of p-NF- $\mathrm{kB} / \mathrm{NF}-\kappa \mathrm{B}$ in macrophages. (C) Quantification of relative protein levels of $\mathrm{p}-\mathrm{I} \mathrm{K} / \mathrm{I} \kappa \mathrm{B}$ in macrophages. (D) Quantification of relative protein levels of $\mathrm{p}-\mathrm{IKK} / \mathrm{IKK}$ in macrophages. (E) Representative images of western blot for $\mathrm{p}-\mathrm{NF}-\kappa \mathrm{B}$ and GAPDH in the cytoplasm of macrophages. (F) Representative images of western blotting for NF- $\mathrm{KB}$ and Histone $\mathrm{H} 3$ in the nuclei of macrophages.

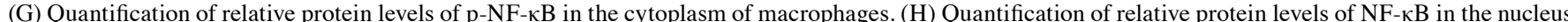

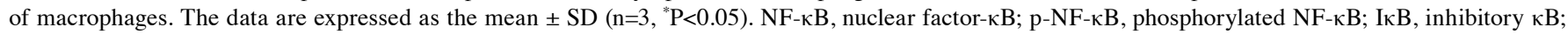
p-IкB, phosphorylated IкB; IKK, inhibitory кB kinase complex; p-IKK, phosphorylated IKK; GAPDH, glyceraldehyde-3-phosphate dehydrogenase.

that sRAGE increased p-IKK level to $1.74 \pm 0.109$ in I/R-treated cells $(n=3 ; P<0.05)$ (Fig. 4A and D). These findings suggested that sRAGE might activate the NF- $\kappa \mathrm{B}$ signaling pathway in macrophages with or without $\mathrm{I} / \mathrm{R}$ treatment. 
A

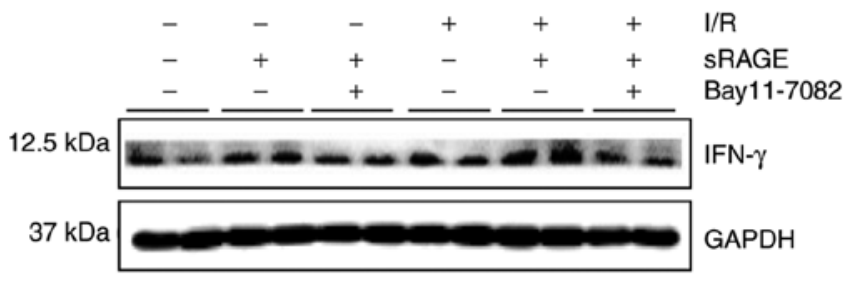

B

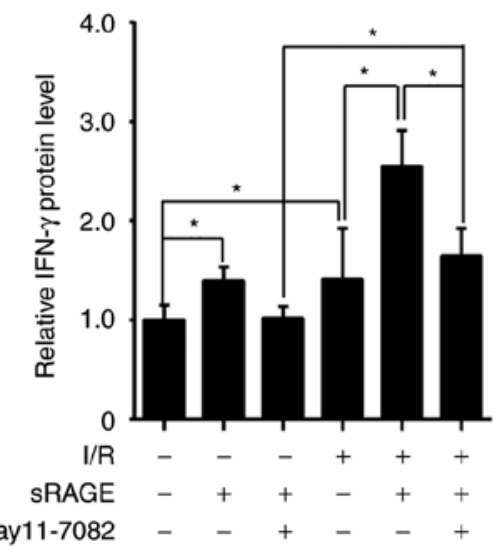

Figure 5. Suppression of NF- $\mathrm{BB}$ abolished the effect of sRAGE on IFN- $\gamma$ expression. (A) Representative images of western blotting for IFN- $\gamma$ in macrophages (B) Quantification of relative protein levels of IFN- $\gamma$ in macrophages. The data are expressed as the mean \pm SD $(n=3$; * $P<0.05)$. sRAGE, soluble receptor for advanced glycation end-products; I/R, ischemia/reperfusion; IFN, interferon; NF- $\mathrm{B}$, nuclear factor- $\mathrm{KB}$.

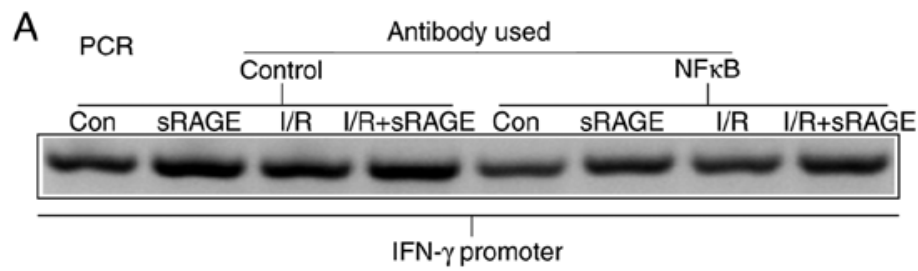

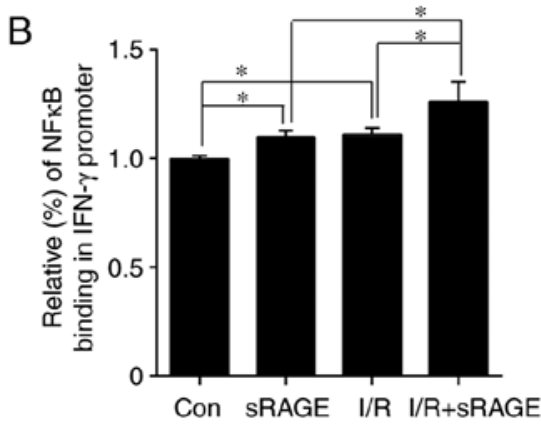

Figure 6. sRAGE induced upregulation of IFN- $\gamma$ by activating NF- $\mathrm{kB}$. (A) Representative images of PCR for the DNA of IFN- $\gamma$ combined with NF-kB in macrophages. (B) Fold-change of IFN- $\gamma$ promoter combined with NF- $\kappa B$ in macrophages. The data are expressed as the mean \pm SD $\left(n=3\right.$; $\left.{ }^{*} \mathrm{P}<0.05\right)$. sRAGE,

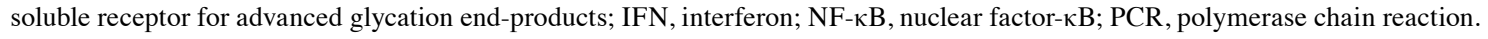

Activation of NF- $\mathrm{KB}$ was also associated with the translocation of NF- $\mathrm{KB}$ into the nucleus. Western blotting was used to detect NF- $\mathrm{KB}$ in the nucleus and phosphorylated (p)-NF- $\mathrm{KB}$ in the cytoplasm in I/R- and sRAGE-treated macrophages. The results showed that nuclear NF- $\mathrm{KB}$ was increased in a time-dependent manner, and that the highest value was reached at $6 \mathrm{~h}(1.83 \pm 0.042)(\mathrm{n}=3 ; \mathrm{P}<0.05)$ (Fig. $4 \mathrm{~F}$ and $\mathrm{H})$. Additionally, the level of $\mathrm{p}-\mathrm{NF}-\kappa \mathrm{B}$ in the cytoplasm was increased from $1.68 \pm 0.033$ at $2 \mathrm{~h}$ to $1.94 \pm 0.087$ at $3 \mathrm{~h}$. Notably, p-NF- $\kappa B$ decreased to the lowest value at $6 \mathrm{~h}(\mathrm{n}=3$; $\mathrm{P}<0.05$ ) (Fig. 4E and $\mathrm{G}$ ). These findings indicated that sRAGE significantly increased the nuclear translocation of NF- $\mathrm{KB}$.

Suppression of NF- $\kappa B$ abolished the effect of sRAGE on IFN- $\gamma$ suppression. To detect the effect of NF- $\mathrm{KB}$ on IFN- $\gamma$ expression, an inhibitor of NF- $\mathrm{kB}$, Bay117082, was simultaneously applied with sRAGE. Western blotting was used to detect the expression of IFN- $\gamma$ in the cells. The results showed that the IFN- $\gamma$ level was significantly increased to $1.41 \pm 0.507$ by I/R treatment compared with the control cells, while sRAGE further increased the IFN- $\gamma$ level to $2.55 \pm 0.360$ in I/R-treated cells, which was inhibited by Bay117082 $(1.64 \pm 0.276)(n=3$; $\mathrm{P}<0.05$ ) (Fig. 5A and B). Additionally, sRAGE alone increased the level of IFN $-\gamma$ to $1.39 \pm 0.139$ in macrophages, which was again inhibited by Bay117082 $(1.02 \pm 0.117)(\mathrm{n}=3 ; \mathrm{P}<0.05)$ (Fig. 5A and B). These findings suggested that the NF- $\mathrm{KB}$ signaling pathway mediates the effects of sRAGE on IFN- $\gamma$ expression in macrophages.

SRAGE induced an upregulation of IFN- $\gamma$ through the activation of $N F-\kappa B$. Notably, p-NF- $\kappa \mathrm{B}$ may regulate gene expression by binding to the $-2,000 \mathrm{bp}$ promoter region of the cytokine. A ChIP assay was used to identify the interaction between NF- $\kappa \mathrm{B}$ and the IFN- $\gamma$ promoter. The results showed that binding between the IFN- $\gamma$ gene and NF- $\kappa \mathrm{B}$ was increased to $1.108 \pm 0.033(n=3 ; P<0.05)$ in $I / R$-treated cells compared with in control cells, and further increased to $1.259 \pm 0.094$ by sRAGE in I/R-treated cells ( $\mathrm{n}=3 ; \mathrm{P}<0.05)$ (Fig. 6). Additionally, sRAGE increased the binding of the IFN- $\gamma$ gene and NF- $\kappa$ B to $1.097 \pm 0.031$ in macrophages $(n=3 ; P<0.05)$ (Fig. 6). Considered together, these findings suggested that sRAGE promoted $\mathrm{NF}-\kappa \mathrm{B}$ binding to the promoter of IFN- $\gamma$.

\section{Discussion}

The purpose of this study was to verify the mechanisms of increased IFN- $\gamma$ expression in I/R-treated hearts by sRAGE, which protected the heart against I/R injury. The result showed that sRAGE improved heart function in I/R-treated mice, which was associated with the recruitment and differentiation of macrophages in myocardial tissues following I/R. These effects contributed to elevated IFN- $\gamma$ expression via activating 
the NF- $\kappa$ B pathway through sRAGE in differentiated M1 macrophage.

To explore the effects of sRAGE in the I/R-treated heart, cardiac function was measured after $\mathrm{I} / \mathrm{R}$ with or without sRAGE in the present study. The results showed that the cardiac output and stroke volume were improved by sRAGE in I/R-treated hearts (Fig. 1A-C). These results were consistent with published work from Dang et al (16).

Previous studies have indicated that sRAGE protected the heart against $I / R$ injury via inducing the recruitment of macrophages and increasing the expression of IFN $-\gamma$ in hearts, as demonstrated by higher numbers of IFN- $\gamma+/ \mathrm{CD} 68+$ macrophages compared with IFN- $\gamma+/ \mathrm{Ly} 6 \mathrm{G}+$ neutrophils and IFN- $\gamma+/ \mathrm{CD} 3+$ lymphocytes via double-immunofluorescent staining in I/R-treated hearts $(16,23)$. The results of the present study also showed that SRAGE increased the recruitment of macrophages in I/R hearts as well (Fig. 1D and E), whilst the myocardial tissue inflammatory response was reduced by sRAGE (Fig. 1D). These results were consistent with published work from Wang et al (24). Furthermore, we also showed that SRAGE reduced neutrophil infiltration following I/R (Fig. 1D and F), which might be due to the dose-dependent action of sRAGE on the chemotactic effects in neutrophils; the results showed that $10 \mathrm{ng} / \mathrm{ml}$ sRAGE promoted the migration of neutrophils (13).

Atpresent, activating phenotypes of macrophages are broadly classified as M1 (classical macrophage) and M2 (alternative macrophage) (25); these are two extreme states. Macrophages may undergo dynamic switches in a variety of diseases; they play diverse roles by producing cytokines to promote or inhibit tissue injury or repair (26-28). Pro-inflammatory M1 macrophages release cytokines such as IFN- $\gamma$ in the early stages of myocardial ischemia, while M2-macrophages release cytokines such as TGF- $\beta$, which promote tumor growth and proliferation as well as tissue repair, and protect the heart and kidneys from I/R injury (29). Strategies targeting macrophage activation or infiltration may be helpful in preventing various diseases following I/R. Pullerits et al (13) demonstrated that sRAGE was an important chemotaxis molecule that may directly interact with MHC-1 to trigger a pro-inflammatory cytokine cascade. Additionally, Wang et al (24) proved that sRAGE induced macrophage infiltration in the murine lung in vivo. Therefore, the effects of sRAGE on the proliferation and differentiation of macrophages were analyzed in the current study, via a 5-BrdU incorporation assay and iNOS staining and the detection of IL-6 and IL-12 mRNA. The results showed that administration of sRAGE promoted the proliferation of macrophages following $\mathrm{I} / \mathrm{R}$, and that $\mathrm{M} 1$ macrophages were dominant in the injured area of I/R at $24 \mathrm{~h}$ (Fig. 2A-F). This might be because of sRAGE, which promotes the differentiation of macrophages into M1-macrophages, which, in turn, increases IFN- $\gamma$ expression in I/R-treated hearts.

Macrophages secrete various cytokines, such as TGF- $\beta$, IFN- $\gamma$, TNF- $\alpha$ and IL-2 (30). Reports have indicated that sRAGE inhibits apoptosis in I/R-induced myocardial tissue via IFN- $\gamma$-induced immunoproteasome activity $(16,31)$. The results of the current study demonstrated that sRAGE enhanced IFN- $\gamma$ expression in macrophages with I/R treatment (Fig. 3). Therefore, it was concluded that sRAGE stimulated macrophages to produce IFN- $\gamma$ to protect the heart against I/R injury.
Thus, there was a need to investigate the cell signaling pathways mediating IFN- $\gamma$ synthesis and release in I/R-treated macrophages. NF- $\mathrm{KB}$ signaling has been reported to regulate the transcription of IFN- $\gamma$ by binding to the promoter region. In this study, the results showed that sRAGE increased both the translocation of NF- $\mathrm{KB}$ into the nucleus and the binding of NF- $\kappa \mathrm{B}$ to the promoter of IFN- $\gamma$. Meanwhile, sRAGE enhanced the expression of IFN- $\gamma$, which was suppressed by the NF- $\kappa B$ inhibitor, Bay117082, in macrophages with $\mathrm{I} / \mathrm{R}$ treatment. However, the NF- $\mathrm{KB}$ inhibitor did not inhibit the expression of IFN- $\gamma$ completely, suggesting that other signaling pathways may be involved in this process. Thus, further studies are needed to clarify the effects of sRAGE on the expression of IFN- $\gamma$.

Besides IFN- $\gamma$, IL- 6 and IL-12 also were increased by sRAGE in I/R-treated hearts, which was reported to be a potential pathological mechanism in cardiac I/R injury, but no cardiac injuries were observed after sRAGE infusion in I/R-treated hearts in the present study. Therefore, it was supposed that IL-6, a cytokine with pro-inflammatory properties, stimulated the growth and differentiation of B-lymphocytes in the spleen, which initiated a protective mechanism after $\mathrm{I} / \mathrm{R}$ in mice as previously reported $(23,32)$. It has been reported that IL-35, a member of the IL-12 family (33), can significantly reduce infarct size after I/R and become a protective immunomodulator in brain ischemic injury in mice. This explained why sRAGE showed protective effects on the I/R-treated heart, even though IL-6 and IL-12 were increased and pro-inflammatory effects were observed in the sRAGE-treated I/R heart. However, no experimental data supporting these hypotheses were recorded, and further studies are needed to demonstrate it.

In conclusion, sRAGE protected the heart from I/R injury; this might be mediated via promoting the infiltration and differentiation of macrophages to M1, which then synthesize and secrete IFN- $\gamma$ via activation of the NF- $\mathrm{KB}$-activated pathway.

\section{Acknowledgements}

The authors would like to thank the other members of the team for their assistance in the present study.

\section{Funding}

This study was supported by the National Natural Science Foundation of China (grant nos. 30801217, 81570321, 81370313, and 81870265), the Beijing Nova Program (grant no. 2010B050), the Beijing Health System High Level Health Technical Personnel Training Program (grant no. 2013-3-046), and the China Young and Middle-aged Clinical Research Foundation (grant no. 2017CCA-VG045).

\section{Availability of data and materials}

All the data generated during this study are included in this published article.

\section{Authors' contributions}

XLZ, CXG, and XJZ designed the experiments. XXC and MQD created the animal ischemia reperfusion model. XLZ 
performed the experiments. HXW, BXC, FHD and HHL analyzed the experimental results. XLZ and XJZ drafted and revised the article. All authors read and approved the final manuscript.

\section{Ethics approval and consent to participate}

All animals received humane care, and the experimental protocol was approved by the Committee of Laboratory Animals according to institutional guidelines of the Use Committee of Capital Medical University.

\section{Patient consent for publication}

Not applicable.

\section{Competing interests}

The authors declare that they have no competing interests.

\section{References}

1. Maneechote C, Palee S, Chattipakorn SC and Chattipakorn N: Roles of mitochondrial dynamics modulators in cardiac ischaemia/reperfusion injury. J Cell Mol Med 21: 2643-2653, 2017.

2. Kocman EA, Ozatik O, Sahin A, Guney T, Kose AA, Dag I, Alatas $\mathrm{O}$ and Cetin $\mathrm{C}$ : Effects of ischemic preconditioning protocols on skeletal muscle ischemia-reperfusion injury. J Surg Res 193: 942-952, 2015.

3. Kunecki M, Plazak W, Podolec P and Golba KS: Effects of endogenous cardioprotective mechanisms on ischemia-reperfusion injury. Postepy Hig Med Dosw (Online) 71: 20-31, 2017.

4. Hauerslev M, Mork SR, Pryds K, Contractor H, Hansen J, Jespersen NR, Johnsen J, Heusch G, Kleinbongard P, Kharbanda $\mathrm{R}$, et al: Influence of long-term treatment with glyceryl trinitrate on remote ischemic conditioning. Am J Physiol Heart Circ Physiol 315: H150-H158, 2018.

5. Wang C, Li H, Wang S, Mao X, Yan D, Wong SS, Xia Z and Irwin MG: Repeated non-invasive limb ischemic preconditioning confers cardioprotection through PKC-/STAT3 signaling in diabetic rats. Cell Physiol Biochem 45: 2107-2121, 2018.

6. Yuan Y, Cao W, Hong Y, Guo X, Wang Y, Wang Y, Wang X and $\mathrm{Xu}$ P: Tilianin pretreatment prevents myocardial ischemia-reperfusion injury via preservation of mitochondrial function in rat heart. Phytomedicine 34: 106-114, 2017.

7. Yang Y,Zhao L and Ma J: Penehyclidine hydrochloride preconditioning provides cardiac protection in a rat model of myocardial ischemia/reperfusion injury via the mechanism of mitochondrial dynamics mechanism. Eur J Pharmacol 813: 130-139, 2017.

8. Cai XY, Lu L, Wang YN, Jin C, Zhang RY, Zhang Q, Chen QJ and Shen WF: Association of increased S100B, S100A6 and $\mathrm{S} 100 \mathrm{P}$ in serum levels with acute coronary syndrome and also with the severity of myocardial infarction in cardiac tissue of rat models with ischemia-reperfusion injury. Atherosclerosis 217: 536-542, 2011.

9. Wautier JL, Zoukourian C, Chappey O, Wautier MP, Guillausseau PJ, Cao R, Hori O, Stern D and Schmidt AM: Receptor-mediated endothelial cell dysfunction in diabetic vasculopathy. Soluble receptor for advanced glycation end products blocks hyperpermeability in diabetic rats. J Clin Invest 97: 238-243, 1996.

10. Dattilo BM, Fritz G, Leclerc E, Kooi CW, Heizmann CW and Chazin WJ: The extracellular region of the receptor for advanced glycation end products is composed of two independent structural units. Biochemistry 46: 6957-6970, 2007.

11. Raucci A, Cugusi S, Antonelli A, Barabino SM, Monti L, Bierhaus A, Reiss K, Saftig P and Bianchi ME: A soluble form of the receptor for advanced glycation endproducts (RAGE) is produced by proteolytic cleavage of the membrane-bound form by the sheddase a disintegrin and metalloprotease 10 (ADAM10). FASEB 22: 3716-3727, 2008.
12. Yonchuk JG, Silverman EK, Bowler RP, Agusti A, Lomas DA, Miller BE, Tal-Singer R and Mayer RJ: Circulating soluble receptor for advanced glycation end products (sRAGE) as a biomarker of emphysema and the RAGE axis in the lung. Am J Respir Crit Care Med 192: 785-792, 2015.

13. Pullerits R, Brisslert M, Jonsson IM and Tarkowski A: Soluble receptor for advanced glycation end products triggers a proinflammatory cytokine cascade via beta2 integrin Mac-1. Arthritis Rheum 54: 3898-3907, 2006.

14. Yan SF, Yan SD, Herold K, Ramsamy R and Schmidt AM: Receptor for advanced glycation end products and the cardiovascular complications of diabetes and beyond: Lessons from AGEing. Endocrinol Metab Clin North Am 35: 511-524, 2006.

15. Schmidt AM, Yan SD, Yan SF and Stern DM: The multiligand receptor RAGE as a progression factor amplifying immune and inflammatory responses. J Clin Invest 108: 949-955, 2001.

16. Dang M, Zeng X, Chen B, Wang H, Li H, Du F and Guo C: Interferon-gamma mediates the protective effects of soluble receptor for advanced glycation end-product in myocardial ischemia/reperfusion. Lab Invest 99: 358-370, 2019.

17. Darwich L, Coma G, Pena R, Bellido R, Blanco EJ, Este JA, Borras FE, Clotet B, Ruiz L, Rosell A, et al: Secretion of interferon-gamma by human macrophages demonstrated at the single-cell level after costimulation with interleukin (IL)-12 plus IL-18. Immunology 126: 386-393, 2009.

18. Deng Y, Chu J, Ren Y, Fan Z, Ji X, Mundy-Bosse B, Yuan S, Hughes T, Zhang J, Cheema B, et al: The natural product phyllanthusmin $\mathrm{C}$ enhances IFN-gamma production by human NK cells through upregulation of TLR-mediated NF-kappaB signaling. J Immunol 193: 2994-3002, 2014.

19. Kim BR, Chun S and Cho D: Association of neutrophil-to-lymphocyte ratio and natural killer cell activity revealed by measurement of interferon-gamma levels in a healthy population. J Clin Lab Anal 33: e22640, 2018.

20. Kang HB, Ahn KS, Oh SR and Kim JW: Genkwadaphnin induces IFN-gamma via PKD1/NF-kappaB/STAT1 dependent pathway in NK-92 cells. PLoS One 9: e115146, 2014.

21. Pan Z, Sun X, Ren J, Li X, Gao X, Lu C, Zhang Y, Sun H, Wang Y, Wang $\mathrm{H}$, et al: miR-1 exacerbates cardiac ischemia-reperfusion injury in mouse models. PLoS One 7: e50515, 2012.

22. Zhang BH, Wang W, Wang H, Yin J and Zeng XJ: Promoting effects of the adipokine, apelin, on diabetic nephropathy. PLoS One 8: e60457, 2013.

23. Brisslert M, Amu S and Pullerits R: Intra-peritoneal sRAGE treatment induces alterations in cellular distribution of CD19(+), CD3 (+) and Mac-1 (+) cells in lymphoid organs and peritoneal cavity. Cell Tissue Res 351: 139-148, 2013.

24. Wang Y, Wang H, Piper MG, McMaken S, Mo X, Opalek J, Schmidt AM and Marsh CB: sRAGE induces human monocyte survival and differentiation. J Immunol 185: 1822-1835, 2010.

25. Ganz T: Macrophage function. New Horiz 1: 23-27, 1993.

26. Ko GJ, Boo CS, Jo SK, Cho WY and Kim HK: Macrophages contribute to the development of renal fibrosis following ischaemia/reperfusion-induced acute kidney injury. Nephrol Dial Transplant 23: 842-852, 2008.

27. Zhang $\mathrm{L}$ and Wang CC: Inflammatory response of macrophages in infection. Hepatobiliary \& pancreatic diseases international. Hepatobiliary Pancreat Dis Int 13: 138-152, 2014.

28. Zhou D, Huang C, Lin Z, Zhan S, Kong L, Fang C and Li J: Macrophage polarization and function with emphasis on the evolving roles of coordinated regulation of cellular signaling pathways. Cell Signal 26: 192-197, 2014.

29. Khan MA, Assiri AM and Broering DC: Complement and macrophage crosstalk during process of angiogenesis in tumor progression. J Biomed Sci 22: 58-67, 2015.

30. Saqib U, Sarkar S, Suk K, Mohammad O, Baig MS and Savai R: Phytochemicals as modulators of M1-M2 macrophages in inflammation. Oncotarget 9: 17937-17950, 2018.

31. Guo CX, Jiang X, Zeng XJ, Wang HX, Li HH, Du FH and Chen BX: Soluble receptor for advanced glycation end-products protects against ischemia/reperfusion-induced myocardial apoptosis via regulating the ubiquitin proteasome system. Free Radic Biol Med 94: 17-26, 2016.

32. Wang Z, Zhou Y, Yu Y, He K and Cheng LM: Lipopolysaccharide preconditioning increased the level of regulatory $B$ cells in the spleen after acute ischaemia/reperfusion in mice. Brain Res 1701: 46-57, 2018.

33. Xu C, Zhu H, Shen R, Feng Q, Zhou H and Zhao Z: IL-35 is a protective immunomodulator in brain ischemic injury in mice. Neurochem Res 43: 1454-1463, 2018. 